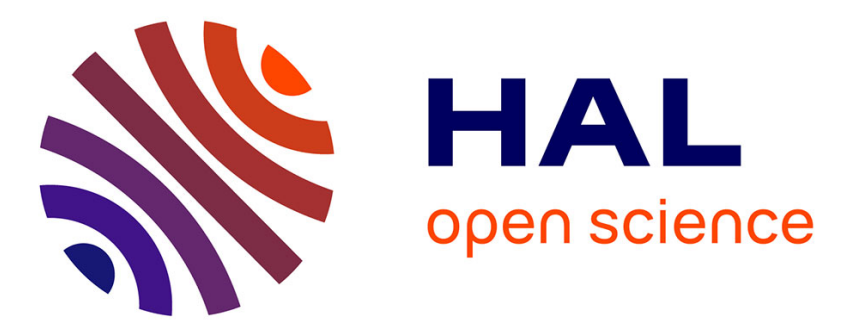

\title{
Savanna domain in the herbivores-fire parameter space exploiting a tree-grass-soil water dynamic model
}

\author{
C. de Michele, F. Accatino, R. Vezzoli, R.J. Scholes
}

\section{To cite this version:}

C. de Michele, F. Accatino, R. Vezzoli, R.J. Scholes. Savanna domain in the herbivores-fire parameter space exploiting a tree-grass-soil water dynamic model. Journal of Theoretical Biology, 2011, 289, pp.74. 10.1016/j.jtbi.2011.08.014 . hal-00739263

\section{HAL Id: hal-00739263 \\ https://hal.science/hal-00739263}

Submitted on 7 Oct 2012

HAL is a multi-disciplinary open access archive for the deposit and dissemination of scientific research documents, whether they are published or not. The documents may come from teaching and research institutions in France or abroad, or from public or private research centers.
L'archive ouverte pluridisciplinaire HAL, est destinée au dépôt et à la diffusion de documents scientifiques de niveau recherche, publiés ou non, émanant des établissements d'enseignement et de recherche français ou étrangers, des laboratoires publics ou privés. 


\section{Author's Accepted Manuscript}

Savanna domain in the herbivores-fire parameter space exploiting a tree-grass-soil water dynamic model

C. De Michele, F. Accatino, R. Vezzoli, R.J. Scholes

PII: S0022-5193(11)00409-7

DOI: doi:10.1016/j.jtbi.2011.08.014

Reference: $\quad$ YJTBI6586

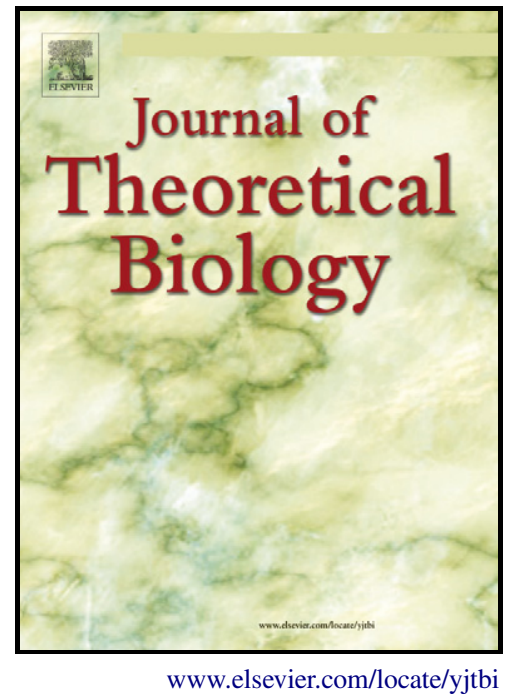

To appear in: $\quad$ Journal of Theoretical Biology

Received date: $\quad 17$ February 2011

Revised date: $\quad 4$ August 2011

Accepted date: 13 August 2011

Cite this article as: C. De Michele, F. Accatino, R. Vezzoli and R.J. Scholes, Savanna domain in the herbivores-fire parameter space exploiting a tree-grass-soil water dynamic model, Journal of Theoretical Biology, doi:10.1016/j.jtbi.2011.08.014

This is a PDF file of an unedited manuscript that has been accepted for publication. As a service to our customers we are providing this early version of the manuscript. The manuscript will undergo copyediting, typesetting, and review of the resulting galley proof before it is published in its final citable form. Please note that during the production process errors may be discovered which could affect the content, and all legal disclaimers that apply to the journal pertain. 


\title{
Savanna domain in the herbivores-fire parameter space exploiting a tree-grass-soil water dynamic model
}

\author{
C. De Michele*,a , F. Accatino ${ }^{\mathrm{a}}$, R. Vezzoli ${ }^{\mathrm{a}}$, R.J. Scholes ${ }^{\mathrm{b}}$ \\ ${ }^{a}$ DIIAR, Politecnico di Milano, P.zza L. da Vinci 32, 20133 Milano, Italy \\ ${ }^{b}$ Natural Resources and the Environment, CSIR, Pretoria, South Africa
}

\begin{abstract}
The tree-grass co-existence in savannas involves multiple and sometimes connected biogeophysical conditions. The savanna domain, its boundaries, and transitions (gradual or abrupt) to other vegetation types (i.e., grassland or forest) are fundamental for the management of ecosystems, and for preserving the biodiversity in present conditions and in future changing scenarios. Here we investigate the savanna domain within grazers-fire and browsers-fire parameter planes through a simple ecohydrological model of tree-grass-soil water dynamics. Stability maps allow to identify savanna domains, and to show the behavior of vegetation under increasing pressure of grazing and browsing. Stability maps shed light on the causes behind possible vegetation abrupt transitions (e.g., forest collapse and bush encroachment). An application to 15 African savannas sites is presented and discussed with the support of a local sensitivity analysis of the model's parameters.

Key words: herbivores, fire, savanna, state transition, gradient, model,

\footnotetext{
*Corresponding author. Tel: +39 0223996233

Email addresses: carlo.demichele@polimi.it (C. De Michele),
} francesco.accatino@mail.polimi.it (F. Accatino), renata.vezzoli@polimi.it (R. Vezzoli), bscholes@csir.co.za (R.J. Scholes)
\end{abstract}


sensitivity analysis

\section{1. Introduction}

2 The dynamics of vegetated ecosystems are controlled and driven by cli3 mate, substrate and disturbances such as fire, herbivory and human activ4 ities. Vegetated ecosystems whose dynamics are dominated by the climate 5 are called climate dependent ecosystems (Bond et al., 2003), whereas in the 6 cases where other perturbations such as fires or herbivores are prominent, 7 they are labeled as fire dependent ecosystems, or consumer controlled ecosys8 tems (Bond et al., 2003, Bond and Keeley, 2005).

9 Where do savannas - that are ecosystems co-dominated by trees and grass 10 - fit in this classification?

11 Field observations (Sankaran et al., 2005, Bucini and Hanan, 2007) reveal 12 a complex situation: savannas can be either climate, or disturbance dependent 13 ecosystems, depending on the environment they occur in.

14 Early models of savannas emphasized the role of soil water availability, 15 and inferred savannas to be climate dependent. Walter (1971) describes sa-

16 vannas as 'broad ecotones' between grasslands and forests depending on the 17 mean annual rainfall; Shmida and Burgess (1988) illustrate the subtropical 18 succession (desert $\rightarrow$ grassland $\rightarrow$ open savanna $\rightarrow$ closed savanna $\rightarrow$ for19 est) as the sequence of ecosystem types observed along a rainfall gradient. 20 In general under these conceptual models, water scarcity permits the co21 existence of trees and grasses by limiting the abundance of trees allowing 22 grass to persist: this is a mechanism of balanced competition (Amarasekare, $232003)$. 
24 More recent works have considered the role of fire in permitting the tree25 grass co-existence in savannas (Hanan et al., 2008, D'Odorico et al., 2006, 26 Bond et al., 2003, Baudena et al., 2010, Accatino et al., 2010), indicating 27 savannas as possible fire dependent ecosystems. In ecosystems where water 28 scarcity already limits the tree density, and allows tree-grass co-existence, fire 29 influences only the tree-grass ratio. On the other hand, if water is sufficient 30 to support the growth of trees, fire can be a limiting factor for tree cover, 31 permitting again the tree-grass co-existence, through a bottleneck mechanism 32 in tree demography. Under these conditions, savannas can be viewed as fire 33 subclimaxes of forests (Scholes and Walker, 1993).

34 Yet other studies have suggested a role for herbivores in maintaining 35 savannas (Scholes and Archer, 1997, Bond and Keeley, 2005, Baxter and 36 Getz, 2005, Holdo, 2007). Particular attention has been paid to elephants, 37 which are able to 're-engineer' the tree layer (Dublin, 1995).

38 Accatino et al. (2010), considering the joint role of rainfall and fire, have 39 suggested that arid savannas are climate dependent, while moist savannas 40 can be fire dependent.

41 In the savanna literature, tree-grass co-existence is often discussed in re42 lation to the existence of multiple steady states. Bifurcation analyses (van 43 Langevelde et al., 2003, Baudena et al., 2010, Accatino et al., 2010) have 44 pointed out the possibility that savannas may represent a bistability con45 dition with forest. Beyond the mathematical formalism, the existence of 46 multiple steady states appears evident in field observations. Among the sev47 eral cases that can be mentioned, we recall the macro-mosaics observable in 48 tropical dry forests, where fire plays a fundamental role in the abrupt tran- 
49 sitions from forest to savanna (Murphy and Lugo, 1986), the savanna-forest 50 hysteresis cycle in the Amazon basin (da Silveira Lobo Sternberg, 2001), and 51 the changes observed in the Serengeti-Maara vegetation due to variations 52 in fire and grazing regimes during the rinderpest pandemic period (Dublin, 53 1995). The key pieces of evidence offered in favor of multiple steady states 54 are abrupt state transitions over time (hysteresis cycles) and space (macro55 mosaics), bimodal state variable frequency or distribution, and the dual re56 sponse to driving parameters (Schröder et al., 2005). The space variability 57 plays an important role in maintaining savannas, and many spatial models 58 were built in order to account the dynamics in space of the vegetation (see 59 e.g., Klausmeier, 1999, Rietkerk et al., 2002, Gilad et al., 2007, Borgogno 60 et al., 2009). However, in this work we point the attention on a spatially 61 implicit model.

62 In particular, we extend the spatially implicit ecohydrological model of 63 water dynamics in a tree-grass-soil system forced by rainfall and fire proposed 64 by Accatino et al. (2010) to explicitly consider disturbances by herbivores, 65 distinguishing grazers from browsers. By doing so, we are able to underline 66 the different contributions of fire and herbivore disturbances to the tree-grass 67 co-existence in savannas.

68 Then, we use stability maps in the grazers-fire and browsers-fire param69 eter planes to identify savanna domains, and to show the behavior of vege70 tation under an increasing pressure of grazing or browsing. In this way, we 71 try to answer fundamental questions about the controls on savanna struc72 ture and function and explore the causes of abrupt transitions in savanna 73 ecosystems dynamics. 
74 We discuss the theoretical results using observed data collected in 15 75 savanna sites and characterized by particularly high or low values of fire 76 occurrences and browsers density. The data are extracted by the database 77 reported in Sankaran et al. (2005). The comparison between model outputs 78 and observed data is commented with the help of a local sensitivity analysis 79 of the model's parameters.

\section{2. The action of fire, grazing and browsing on savannas}

81 Fires and herbivores are 'direct' disturbances to the demography of veg82 etated ecosystems (Hobbs and Huenneke, 1992). The interactions among 83 rainfall, fire and herbivores in shaping the vegetation are sketched in Fig. 84 1(a). Fires shape savanna structure by acting as a determinant of the tree 85 layer composition (Frost et al., 1986, Bond and van Wilgen, 1996). The 86 quantity of tree biomass is, in general, negatively correlated with the fire

87 frequency (Scholes and Walker, 1993). The spread and intensity of fire is 88 supported by the abundance of dead grasses (fuel load) during the dry sea89 sons (Scholes and Archer, 1997, Govender et al., 2006). Fires seldom damage 90 adult trees, but knock back or kill tree seedlings and saplings in the flame 91 zone, the height of which is determined by the abundance of dead grass.

92 Thus fires act as a demographic bottleneck, restricting the recruitment of 93 small trees to the adult class.

94 Large mammal herbivores in African savannas form a continuum from 95 eaters of grass only (grazers) to eaters of trees only (browsers) (McNaughton 96 and Georgiadis, 1986). It is nevertheless useful to split them into two dis97 crete classes, grazers and browsers, to evidence their different feedbacks on 
98 fire via the quantity of dead grass (fire's fuel load). Grazers directly reduce

99 the quantity of dead grass which controls the spread and intensity of fires,

100 which in turn reduces tree recruitment (negative feedback of grazers on fire),

101 see Fig. 1(b). Browsers indirectly increase fuel load (positive feedback of

102 browsers on fire) reducing the competitive effect of trees on grass production

103 (Scholes and Archer, 1997, van Langevelde et al., 2003), see Fig. 1(c). The

104 decline of woodlands in presence of browsers has been widely documented,

105 e.g., in East Africa (Laws, 1970), in Ruaha National Park (Barnes, 1983),

106 in Botswana (Ben-Shahar, 1993, Skarpe et al., 2004), in Serengeti-Maara

107 (Dublin, 1995), and in Etosha National Park (de Beer et al., 2006). Among

108 browsers, the elephants Loxodonta africana have the most dramatic impacts

109 on the woody vegetation, leading to the so-called 'Elephant problem'. Ele-

110 phants impacts are more marked when they have been confined within a

111 remnant of a formerly wider range (Dublin, 1995). 


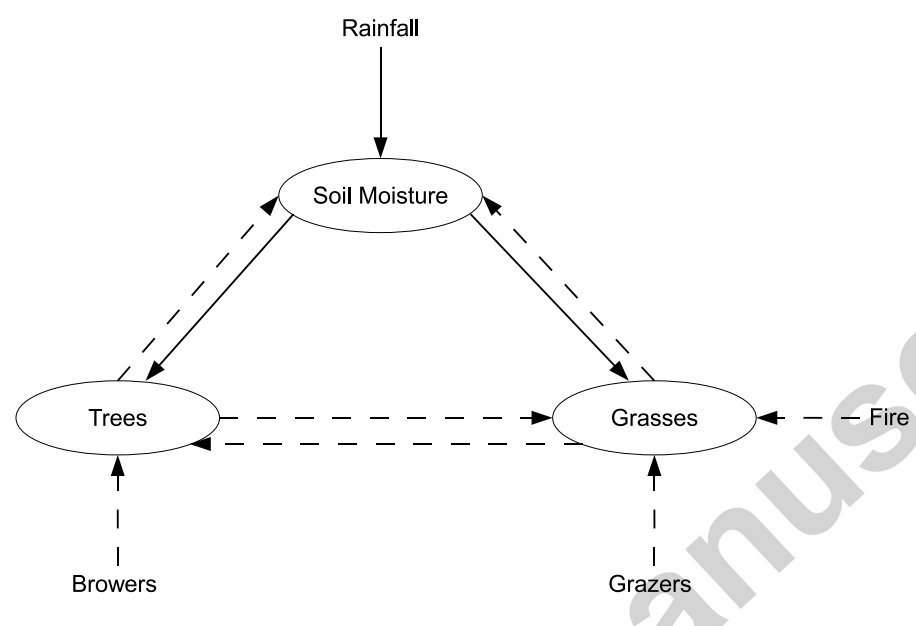

(a)

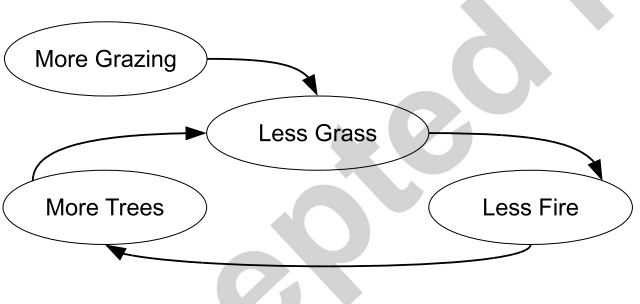

(b)

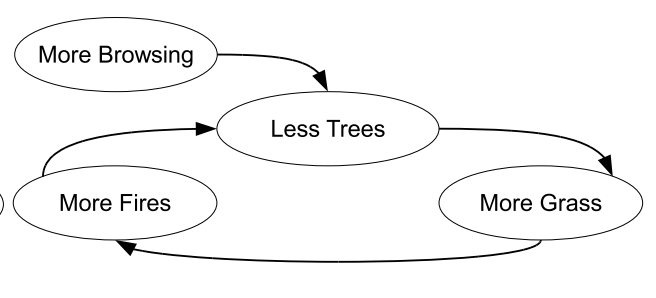

(c)

Figure 1: Panel (a) sketches interactions among rainfall, fire, herbivores, soil moisture, trees and grass. Continuous (dashed) lines indicate positive (negative) interactions. Panels (b) and (c) show respectively feedbacks of grazers-fire and browsers-fire on trees and grass. 


\section{3. Ecohydrological model of tree-grass dynamics}

113 We represent the tree-grass dynamics by a minimal ecohydrological model

114 introduced by Accatino et al. (2010). This model implicitly considers trees

115 as superior competitors for space (in the sense of Tilman, 1994) since they

116 can overtop grass; while it explicitly models the competition between trees

117 and grass for soil water within the root zone, and the differential disturbance

118 action of fire on grass and trees. The model has been slightly modified to

119 explicitly consider also the role of grazers and browsers on grass and trees

120 respectively. The state variables are three: 1) the soil water content, $S$,

121 within the pore volume of a column of soil unitary area with depth equal to

122 the root zone, 2) the fractions of area covered by trees, $T, 3)$ the fractions

123 of area covered by grass, $G$. All the state variables are dimensionless and

124 range between 0 and 1 (a further condition is $0 \leq T+G \leq 1$ ). The tree-

125 grass-soil water dynamics are mathematically described by the following set

126 of differential equations:

$$
\left\{\begin{array}{l}
\frac{d S}{d t}=\frac{p}{w_{1}}(1-S)-\epsilon S(1-T-G)-\tau_{T} S T-\tau_{G} S G \\
\frac{d T}{d t}=\gamma_{T} S T(1-T)-\delta_{T 0} T-b T-\delta_{F} f G T \\
\frac{d G}{d t}=\gamma_{G} S G(1-T-G)-\gamma_{T} S T G-\delta_{G 0} G-g G-f G
\end{array}\right.
$$

127 The first row of Eq.(1) represents the soil water balance in the pore volume

$128\left(w_{1}\right)$ having unitary area and as depth the root zone. The term $p / w_{1}$ is the

129 rainfall input where $p[\mathrm{~mm} / \mathrm{yr}]$ is the mean annual rainfall, and $p / w_{1} S$ is the

130 leakage, modelled as linearly dependent on $S$ to keep the model analytically

131 tractable. The terms $\epsilon S(1-T-G), \tau_{T} S T, \tau_{G} S G$ are representative respec- 
132 tively of evaporation from bare soil fraction $(1-T-G)$, water uptake from 133 tree fraction, and grass fraction. The maximum water uptake parameters $\epsilon$, $134 \tau_{T}$, and $\tau_{G}$, all in units $[1 / \mathrm{yr}]$, are representative of the potential evapotran135 spiration terms scaled by $w_{1}$. The second and third rows in Eq.(1) describe 136 the dynamics of trees and grass, respectively. Tree growth term $\gamma_{T} S T(1-T)$ 137 is proportional to the fraction of soil not occupied by trees $(1-T)$, i.e., trees 138 can overtop grass, and grass growth term $\gamma_{G} S G(1-T-G)$ is proportional to 139 the bare soil fraction $(1-T-G)$. The tree fraction is reduced by senescence $140 \delta_{T 0} T$, browsing activity $b T$ and fires $\delta_{F} f G T$, where $f G$ is representative of 141 the fuel load. The grass fraction is reduced by tree capability to displace 142 grass $\gamma_{T} S T G$, senescence $\delta_{G 0} G$, grazing activity $g G$, and fires $f G$. In partic143 ular, $\gamma_{T}$ and $\gamma_{G}$ represent the potential growth rate for trees and grass, $\delta_{T 0}$ 144 and $\delta_{G 0}$ are the disappearance rates in the absence of fire and herbivores. For 145 the trees equation, $b$ is an additional removal rate representing browsing, or 146 tree harvesting, while $\delta_{F}$ represents the tree vulnerability to fires. Similarly 147 in the grass fraction equation, the additional removal rate is $g$ and repre148 sents grazing, while $f$ is the fire frequency. All parameters of the second and 149 third rows carry dimensions of $[1 / \mathrm{yr}]$ except $\delta_{F}$ that is dimensionless. All the 150 parameters of Eq.(1) are positively defined.

151 Equation (1) admits five steady state solutions (i.e., $d S / d t=d T / d t=$ $152 d G / d t=0)$, but only four satisfy the conditions $0 \leq T \leq 1,0 \leq G \leq 1$, and $1530 \leq T+G \leq 1$. Of these, the first solution is characterized by the absence 154 of vegetation, and we will refer to it as unvegetated, i.e. $T=0, G=0$. The 155 second solution has grass only, i.e. (desert) grassland, $T=0,0<G \leq 1$. 156 The third solution has trees only, i.e. forest, $0<T \leq 1, G=0$. The 
157 fourth solution has a co-existence of tree and grass, i.e. savanna, $0<T<1$, $1580<G \leq 1-T$. The steady states are available analytically (not reported 159 here for brevity). A linear stability analysis of the steady states has been 160 performed evaluating the eigenvalues of the Jacobian matrix associated to 161 the model. In particular, if the real part of all the eigenvalues is strictly 162 negative, the steady state is stable. For further details about the model and 163 parameters' values see Accatino et al. (2010).

164 In the following section, we will assume as reference values for the pa165 rameters: $p=700[\mathrm{~mm} / \mathrm{yr}] w_{1}=345[\mathrm{~mm}], \epsilon=20[1 / \mathrm{yr}], \tau_{T}=30[1 / \mathrm{yr}]$, $166 \tau_{G}=10[1 / \mathrm{yr}], \gamma_{T}=2[1 / \mathrm{yr}], \gamma_{G}=200[1 / \mathrm{yr}], \delta_{T 0}=0.02[1 / \mathrm{yr}], \delta_{G 0}=2$ $167[1 / \mathrm{yr}]$, and $\delta_{F}=0.35$, while $b$ varies between 0 and $0.1[1 / \mathrm{yr}]$ and $g$ between 1680 and $10[1 / \mathrm{yr}]$. Note that the total removal terms, i.e., $\delta_{G 0}+g$ and $\delta_{T 0}+b$, 169 may exceed the range indicated by Accatino et al. (2010), under conditions of 170 a high level of disturbances - a situation of particular interest in the present 171 work.

172 Annual rainfall, fire, and herbivores are environmental forcings treated 173 here as constants. However, rainfall and fire are stochastic variables as prop174 erly assumed by Fernandez-Illescas and Rodriguez-Iturbe (2003) for the rain175 fall forcing, by D'Odorico et al. (2006), Hanan et al. (2008) for fire. Herbi176 vores are more properly considered as dynamic state variables whose abun177 dance depends on the resource availability as treated in May (1977), van de 178 Koppel et al. (1997). The stochastic behavior of the environmental forcings, 179 like rainfall and fire, could be considered through a statistical dynamical 180 approach as outlined by De Michele et al. (2008) and Vezzoli et al. (2008).

181 The dynamical behavior of herbivores could be treated by adding new state 
182 variables to the present model. The deterministic variable-parsimonious ap-

183 proach, we have adopted here, provides results that can be easily extended

184 in a more realistic dynamic-stochastic framework. This extension, however,

185 is out the scope of the present work, and it will be considered in a future

186 study.

\section{4. Where are savannas in the herbivores-fire space?}

188 Accatino et al. (2010) have investigated the existence and the stability of 189 savannas with respect to rainfall and fire forcings (i.e., in the parameter plane $190 p-f)$ showing that savanna is stable for low values of rainfall $(100 \leq p \leq 600$ $191[\mathrm{~mm} / \mathrm{yr}])$ and fire $(0.2 \leq f \leq 0.8[1 / \mathrm{yr}])$. In this region, savannas are the 192 result of a limited water availability, and are climate dependent ecosystems.

193 Conversely, for high values of rainfall $(600<p \leq 1100[\mathrm{~mm} / \mathrm{yr}])$ and fire

$194(f>0.8[1 / \mathrm{yr}])$, savanna is in bistability with forest. In this case, savannas 195 are permitted by the frequent fire disturbances making them fire dependent 196 ecosystems.

197 In the current work, the savanna domain is explored with respect to 198 disturbances, herbivores and fire, with the aim of clarifying the savanna 199 steady state stability with different types and levels of disturbances. In the 200 following two subsections, the stability maps in the planes $g-f$ and $b-f$ are 201 derived and presented in panels (a) of Figs. 2 and 3, respectively. Stability 202 maps will be used to study the changes of the vegetation composition along 203 gradients of grazing and browsing pressure. The change in the values of tree 204 and grass fractions at a fire frequency level of $f=0.5[1 / \mathrm{yr}]$ will be discussed 205 in the light of savanna ecosystems transitions, e.g., pathways J-M and L-K 
206 in panels (b) and (c) of Fig. 2 or pathways Z-X and Y-W in panels (b) and 207 (c) of Fig. 3.

208 In Fig. 2 the parameter $g$ varies from 0 to $10[1 / \mathrm{yr}]$ and browsing is $209 \operatorname{absent}(b=0[1 / \mathrm{yr}])$. In Fig. 3 the parameter $b$ varies from 0 to $0.1[1 / \mathrm{yr}]$, 210 and grazing is absent $(g=0[1 / \mathrm{yr}])$. The fire frequency, $f$, varies from 0 to $2111.2[1 / \mathrm{yr}]$ for both maps.

212 They show five regions, three of them are characterized by one stable 213 state: grassland $(\mathrm{G})$, savanna $(\mathrm{S})$, and forest $(\mathrm{F})$, while the remaining ones 214 by two alternative stable states (regions of bistability): savanna/forest (S/F) 215 and grassland/forest $(\mathrm{G} / \mathrm{F})$. The qualitatively symmetrical behavior of the 216 stability maps in the parameter space $g-f$, Fig. $2(a)$, and $b-f$, Fig.

$2173(\mathrm{a})$, derives from the use of the same functional form to represent grazers $218(-g G)$ and browsers $(-b T)$ effects respectively on the state variables $G$ and $219 T$, as underlined in Figs. 1(b) and 1(c). If grass removal rate $g$ increases, 220 the possibility of trees to completely displace grass is enhanced. Conversely, 221 if trees removal rate $b$ is increased, the grass competitiveness for space is 222 enhanced, thus savanna and grassland ecosystems appear for high values of 223 b. A similar symmetrical behavior is expected drawing the stability maps in $224 \gamma_{G}-f$ and $\gamma_{T}-f$ parameter spaces.

225 4.1. Stability map in the grazers-fire space

226 In the plane $g-f$, Fig. 2(a), savanna is stable in the bottom-left side of the 227 panel (region $\mathrm{S}$ ) within the domain $0 \leq f \lesssim 0.9[1 / \mathrm{yr}]$ and $0 \leq g \lesssim 2[1 / \mathrm{yr}]$, 228 where the last upper limit depends on the right boundary of the region. In 229 this region the co-existence mechanism is the balanced competition, because 230 the tree growth is limited by the water scarcity and grass (provided that the 
231 grazing off-take is sufficiently low) is still able to grow. Moreover, the light 232 grazing allows the accumulation of dead grass which fosters more frequent 233 and severe fires further limiting the tree fraction.

234 Grassland is stable in the top-left side of the panel (region G), for $f \gtrsim 0.9$ $235[1 / \mathrm{yr}]$ and $g \lesssim 1[1 / \mathrm{yr}]$. Here the high fire frequency and the low grazing 236 level lead to the exacerbation of balanced competition mechanisms causing 237 the absence of trees. Thus, at low grazing pressure, fire is fundamental in 238 maintaining grasslands (Zimmermann et al., 2009).

239 The vegetation change from an herbaceous environment to a mixed tree240 grass landscape, observed at the time of the rinderpest pandemic (late $19^{\text {th }}$ 241 century) in Masai Mara, can be discussed using the grazers-fire plane. As 242 described in Dublin (1995), at the end of $19^{\text {th }}$ century, the ecosystem was a 243 grassland under high levels of grazing and human induced fires. When the 244 rinderpest virus began to spread, cattle and wild herbivores died, the human 245 population declined, having as consequence a reduction in grazing activity 246 and human induced fires. Thus, trees appeared and spread converting the 247 ecosystem into a savanna state - a shift from region $(\mathrm{G})$ to region $(\mathrm{S})$ in Fig. $2482(\mathrm{a})$.

249 Forest state is stable in the bottom-right side of the panel (region F). 250 Grazing pressure is so high that, though the tree fraction may be at its 251 bioclimatic limit as imposed by the water scarcity, grass does not have any 252 chance to survive. Within this region the tree fraction is independent of the 253 fire frequency $(f)$ and the grazing level $(g)$.

254 The bistability region $(\mathrm{G} / \mathrm{F})$ located in the top-right side of the panel, 255 presents grassland and forest as potential states. Similarly region (S/F) 
256 presents two alternative steady states: savanna and forest. The bistability

257 implies that a small perturbation of the environmental forcings can provoke

258 an abrupt transition from one state to another, resulting in changes in the

259 landscape at the macro-scale. In both bistability regions, grass can survive

260 because fires prevent the tree domination, causing a bottleneck in tree de-

261 mography. Thus, these are fire dependent ecosystems. On the other side, the

262 achievement of the forest state is possible thanks to the feedback illustrated 263 in Fig. 1(b).

264 Panels (b) and (c) of Fig. 2 represent respectively the steady states of 265 tree and grass fractions along a grazing gradient at fire frequency $f=0.5$

266 [1/yr]. Starting from point A (savanna), increasing the grazing level, first the

267 point $\mathrm{K}$ is reached, and thence the abrupt transition $\mathrm{K}-\mathrm{L}$ occurs leading the

268 system to the forest state (point L). Transitions like K-L (i.e., the invasion of

269 woody species into the grass stratum) are widely encountered in the savanna

270 literature under the name of bush encroachment (Skarpe, 1990, Prins and

271 van der Jeugd, 1993, Smit, 2004, Wiegand et al., 2005, Coetzee et al., 2008,

272 among others). Bush encroachment has been associated with periods of

273 high rainfall (O'Connor, 1995), following after periods of drought during

274 which there was high grazing pressure by domestic livestock (Moleele and

275 Perkins, 1998, Roques et al., 2001). Grazers would promote the dominance

276 of trees over grass, directly, by removing grass and, indirectly, by reducing

277 the amount of available fuel load (dead grasses). Moleele and Perkins (1998)

278 report that in a non-grazed zone fires are more frequent than in adjacent

279 encroached zones, probably because of the reduced presence of dead grass in

280 the latter. 
281 Transitions like M-J can characterize also other phenomena able to in282 crease the overall tree removal rate (e.g. harvesting for timber or domestic 283 fuel) that facilitate the grass presence and the tree-grass co-existence. This 284 condition is widespread in the most densely-settled rural savanna regions. 


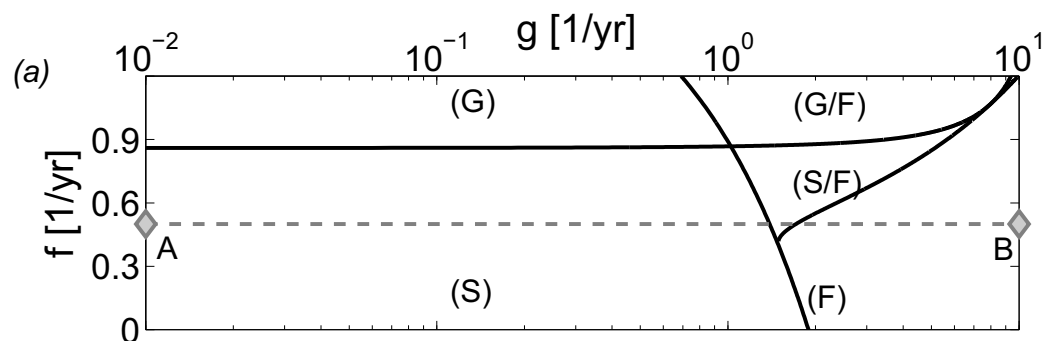

(b)
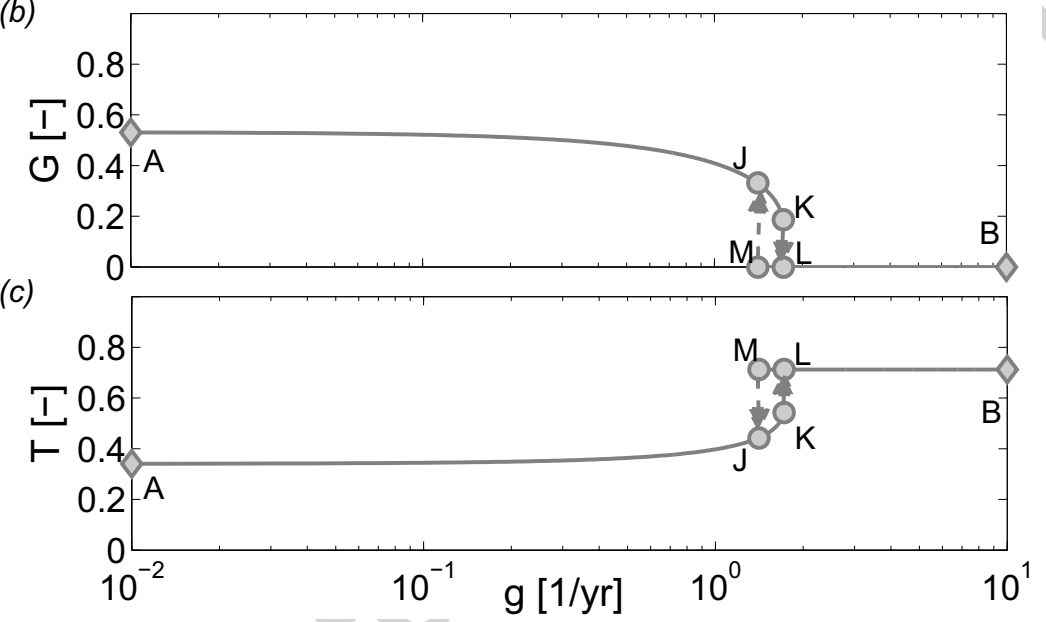

Figure 2: Type of vegetation in the grazers-fire parameter plane. Panel (a) gives the stability map in the plane $g-f$. Panels (b) and (c) provide changes in vegetation structure over the grazing gradient $\mathrm{A}-\mathrm{B}$ at fire frequency $f=0.5[1 / \mathrm{yr}]$ : panel $(\mathrm{b})$ shows grass fraction, while panel (c) the tree fraction. Transitions K-L and M-J are described at the end of the Stability in the grazers-fire space paragraph. The parameters values are $p=700$ $[\mathrm{mm} / \mathrm{yr}], w_{1}=345[\mathrm{~mm}], \epsilon=20[1 / \mathrm{yr}], \tau_{T}=30[1 / \mathrm{yr}], \tau_{G}=10[1 / \mathrm{yr}], \gamma_{T}=2[1 / \mathrm{yr}]$, $\gamma_{G}=200[1 / \mathrm{yr}], \delta_{F}=0.35, \delta_{T 0}=0.02[1 / \mathrm{yr}], b=0[1 / \mathrm{yr}], \delta_{G 0}=2[1 / \mathrm{yr}]$. 
285

286

287

288

289

290

291

292 in absence of fire, $f=0[1 / \mathrm{yr}]$. In other words, the presence of browsers is

293 sufficient to prevent the formation of a woodland (Scholes and Archer, 1997).

294 In region $(\mathrm{G})$ of Fig. 3(a), grassland is stable in the top-right side for 295

296 high fire frequency that enhances the browsing-fire feedback shown in Fig.

297 1(c). In region $(\mathrm{F})$, forest is stable in the bottom-left side for small values of

$298 f(\lesssim 0.6[1 / \mathrm{yr}])$ and $b$ varying between 0 and $0.004[1 / \mathrm{yr}]$. In this case the

299 browsing level is not enough to balance the competitive pressure of trees on

300 grass for space and water.

301 In region (S/F) of Fig. 3(a), characterized by $0.6 \lesssim f \lesssim 0.9[1 / \mathrm{yr}]$ and $302 b \lesssim 0.01[1 / \mathrm{yr}]$, savanna and forest are the alternative stable states. In this 303 region, fire is sufficient to prevent the closure of the tree canopy, whereas 304 browsing pressure alone is insufficient. In region $(G / F)$, characterized by $305 f \gtrsim 0.9[1 / \mathrm{yr}]$ and $b \lesssim 0.01[1 / \mathrm{yr}]$, fire can cause the extinction of trees. 306 Savannas and grasslands found in these bistability regions are fire dependent 307 ecosystems.

308 Panels (b) and (c) of Fig. 3 represent respectively the steady states of 309 grass and tree fractions respectively along a browsing gradient at $f=0.5$ 
310 [1/yr]. Moving along the browsing gradient from point $\mathrm{C}$ (forest) to point

311 D (savanna), the bistability region $(\mathrm{S} / \mathrm{F})$ is crossed, and the steady state 312 is dependent on the initial condition. If the initial state is forest (point

313 C) grasses remain absent as long as the browsing pressure is below 0.006

314 [1/yr], (line C-X-Y in Fig. 3(b)). For further increases of $b$, the tree-grass

315 co-existence is possible (line W-D in Figs. 3(b) and 3(c)) and the savanna

316 state is reached. The transition between forest (point Y) and savanna (point

317 W) is abrupt. Conversely, if the initial state is savanna, point D in panels

318 (b) and (c) of Fig. 3, a browsing pressure above 0.0011 [1/yr] supports

319 the savanna state (line D-W-Z in Fig. 3(b)), while for $b<0.0011[1 / \mathrm{yr}]$

320 grasses disappear and only trees are present at the equilibrium (line X-C).

321 The transition between savanna (point Z) and forest (point X) is also abrupt.

322 An example of the hysteresis cycle Y-W-Z-X may be the cyclic elephants-

323 vegetation dynamics hypothesized by Caughley (1976). Elephants can cause

324 a forest/woodland collapse (transition Y-W). The recovery of the woody

325 fraction (transition Z-X) is possible only reducing the browsers pressure,

326 e.g., when the elephants move to a different place. 

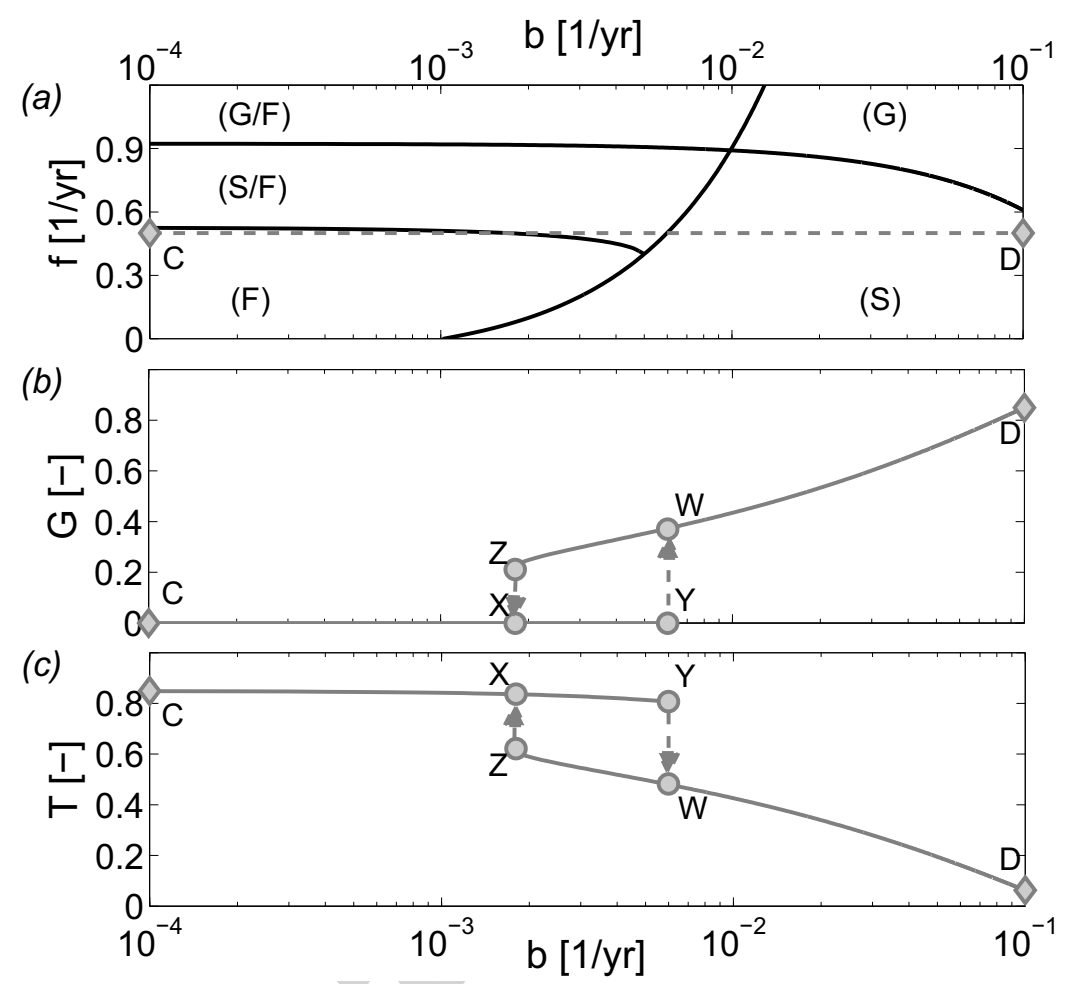

Figure 3: Vegetation type in the browsers-fire parameter plane. Panel (a) gives the stability map in the plane $b-f$. Panels (b) and (c) provide changes in vegetation structure over the browsing gradient C-D at fire frequency $f=0.5[1 / \mathrm{yr}]$ : panel (b) shows grass fraction, while panel (c) the tree fraction. Transitions X-Y and Y-W are described at the end of the Stability in the browsers-fire space paragraph. The other parameters values are $p=700$ $[\mathrm{mm} / \mathrm{yr}], w_{1}=345[\mathrm{~mm}], \epsilon=20[1 / \mathrm{yr}], \tau_{T}=30[1 / \mathrm{yr}], \tau_{G}=10[1 / \mathrm{yr}], \gamma_{T}=2[1 / \mathrm{yr}]$, $\gamma_{G}=200[1 / \mathrm{yr}], \delta_{F}=0.35, \delta_{T 0}=0.02[1 / \mathrm{yr}], \delta_{G 0}=2[1 / \mathrm{yr}]$ and $g=0[1 / \mathrm{yr}]$. 


\section{5. Case studies}

328 Here we examine a set of 15 sites contained in the Sankaran et al. (2005) 329 database, which includes 854 savanna sites from all over the African conti330 nent. For each of the 854 sites, measurements of mean annual rainfall, fire

331 frequency, and woody cover are available, but information on the biomass of 332 herbivores is available only for 129 of the sites; in particular, we are concerned 333 with information on browsers.

334 For this reason, we selected 15 sites characterized by particularly high or 335 low values of browsers biomass $(\mathcal{B})$ and fire frequency $(f)$. Specifically, we 336 mean for 'low' fire frequency values of $f<0.05[1 / \mathrm{yr}]$, and 'low' browsing 337 density $\mathcal{B}<100\left[\mathrm{~kg} / \mathrm{km}^{2}\right]$; whereas for 'high' fire frequency values of $f \geq 0.5$ $338[1 / \mathrm{yr}]$ and 'high' browsing density $\mathcal{B} \geq 900\left[\mathrm{~kg} / \mathrm{km}^{2}\right]$.

339 Consequently, we examine four disturbance regimes: i) low browsing and 340 low fire frequency (hereinafter referred to as L-L and indicated with • in Figs. 341 4-7); ii) high browsing and low fire frequency (H-L, o); iii) high browsing and 342 high fire frequency $(\mathrm{H}-\mathrm{H}, \diamond)$; iv) low browsing and high fire frequency (L-H, 343 ). Figure 4 gives the geographical location of the 15 sites. Four of them are 344 in Ivory Cost (region A), five in Kenya (region B) and six in South Africa 345 (region $\mathrm{C}$ ). Table 1 reports the main information about the 15 sites and 346 indication of the disturbances regime. 


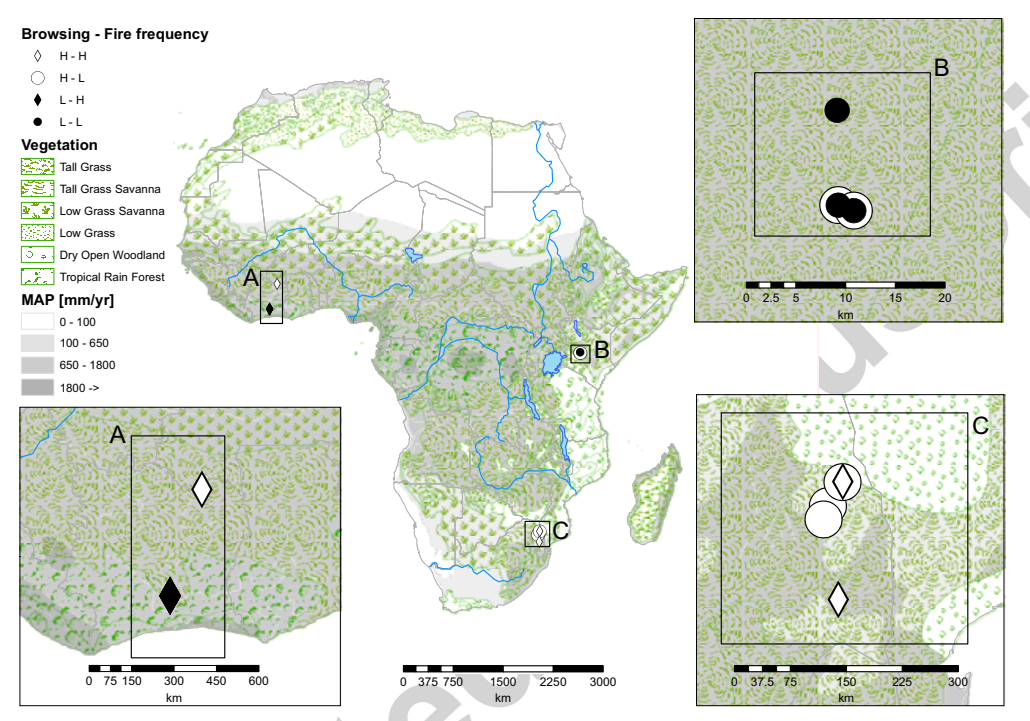

Figure 4: Location of the 15 African sites considered in Ivory Coast (A), Kenya (B), and South Africa (C). Sites symbology is representative of the disturbances regime: L-L (•), $\mathrm{H}-\mathrm{L}(\mathrm{\circ}), \mathrm{H}-\mathrm{H}(\diamond)$ and L-H $(\diamond)$. 
Table 1: Values of the main variables in the 15 African sites, after Sankaran et al. (2005). Sites labeled as A are in Ivory Coast, B in Kenya and C in South Africa. The acronymous CNP stands for Comoé National Park, MRC for Mpala Research Center, KNP for Kruger National Park.

\begin{tabular}{llccccc}
\hline Site & Location & MAP & $\begin{array}{c}\text { Woody } \\
\text { Cover }\end{array}$ & $\begin{array}{c}\text { Fire return } \\
\text { period }\end{array}$ & $\begin{array}{c}\text { Browsers } \\
\text { biomass }\end{array}$ & $\begin{array}{c}\text { Disturbance } \\
\text { regime }\end{array}$ \\
& & & {$[\mathrm{mm} / \mathrm{yr}]$} & {$\left[\mathrm{kg} / \mathrm{km}^{2}\right]$} & \\
\hline A1 & Lamto & 1163 & 5.5 & 1 & 88 & L-H \\
A2 & Lamto & 1163 & 14.7 & 1 & 88 & L-H \\
A3 & Lamto & 1163 & 40.1 & 1 & 88 & L-H \\
A4 & CNP & 943 & 30 & 1 & 1035 & H-H \\
B1 & MRC & 469 & 41.3 & $>20$ & 0 & L-L \\
B2 & MRC & 469 & 29.2 & $>20$ & 4768 & H-L \\
B3 & MRC & 530 & 45 & $>20$ & 0 & L-L \\
B4 & MRC & 530 & 29.8 & $>20$ & 4768 & H-L \\
B5 & MRC & 366 & 40.1 & $>20$ & 0 & L-L \\
C1 & Klaserie & 465 & 41 & $>10$ & 1000 & H-L \\
C2 & Klaserie & 500 & 35 & $>10$ & 2000 & H-L \\
C3 & KNP & 485 & 19.55 & $>50$ & 907 & H-L \\
C4 & KNP & 497 & 6.14 & 1 & 943 & H-H \\
C5 & KNP & 510 & 1.7 & 1 & 1016 & H-H \\
C6 & KNP & 435 & 51.9 & 22.25 & 38 & L-L \\
\hline
\end{tabular}


347 The four sites, hereinafter referred as A1, A2, A3 and A4, in Ivory Coast 348 (region A) are characterized by a tall grass savanna ecosystem. The sites 349 A1, A2, and A3, located in Lamto Research Station, are characterized by a 350 mean annual rainfall of about $1160[\mathrm{~mm} / \mathrm{yr}]$ and the vegetation is a mosaic 351 of grass, shrub, and tree savannas on the edge of rain forests (Abbadie et al., 352 2006). The fourth site, A4, is located at the Comoé National Park, and is 353 characterized by a mean annual rainfall of about $950[\mathrm{~mm} / \mathrm{yr}]$, high browsers 354 density (about $1035\left[\mathrm{~kg} / \mathrm{km}^{2}\right]$ ), and a fire return period of 2 years, Sankaran 355 et al. (2005). The Comoé National Park vegetation is a mosaic of dense 356 shrubby savanna, forest islands, and gallery forests along the main rivers. 357 The 'climax' vegetation of this area would be semi-deciduous forest, but its 358 development is prevented by fires (Hovestadt et al., 1999).

359 The five sites, B1 to B5, are located at Mpala Research Centre in Kenya 360 (region B), and are characterized by a mean annual rainfall varying from 361 north to south between $366[\mathrm{~mm} / \mathrm{yr}], \mathrm{B} 5$, and $530[\mathrm{~mm} / \mathrm{yr}], \mathrm{B} 3$ and B4, and 362 a fire return period greater than 20 years, see Table 1. A bushland community 363 covers $99 \%$ of the landscape consisting of a discontinuous layer of perennial 364 grasses and a shrub layer. The remaining 1\% of the landscape is dominated 365 by short-grasses (Augustine and McNaughton, 2006).

366 The South African sites (region C), C1 to C6, are located in the north367 east 'lowveld', two of them, C1 and C2 are in the Klaserie reserve adjacent 368 to Kruger National Park where are located sites C3, C4, C5, and C6. From 369 north to south the mean annual rainfall varies between 435 [mm/yr] (site 370 C6) and 510 [mm/yr] (site C5). The site C6, in the Kruger National Park, 371 is characterized by a browsers density of $38\left[\mathrm{~kg} / \mathrm{km}^{2}\right]$ and a fire frequency of 
$3720.04[1 / \mathrm{yr}]$. The sites C1 and C2 are in the Klaserie reserve, with a browsers

373 density of 1000 and $2000\left[\mathrm{~kg} / \mathrm{km}^{2}\right]$ and a fire frequency of $0.1[1 / \mathrm{yr}]$, and site

374 C3 is in Kruger National Park with browsers density equal to $907\left[\mathrm{~kg} / \mathrm{km}^{2}\right]$

375 and a fire return period of about 50 years (Biggs et al., 2003). The sites

376 C4 and C5, both in Kruger National Park, are characterized by a browsers

377 density of about $1000\left[\mathrm{~kg} / \mathrm{km}^{2}\right]$ and a fire return period of 1 year (Sankaran

378 et al., 2005).

379 Figure 5 shows the 15 sites in the mean annual rainfall - woody cover

380 plane, where the line represents the piecewise linear regression on the 99th

381 quantile as in Sankaran et al. (2005). The upper limit of woody cover is

382 approximately linearly dependent on the mean annual precipitation when is

383 below $650[\mathrm{~mm} / \mathrm{yr}]$, and independent above this value. The piecewise linear

384 regression is representative of the maximum woody cover attainable for a

385 given mean annual rainfall in the absence of disturbances. Ecosystems close

386 to this limit are climate dependent. An ecosystem represented by a point

387 below the piecewise linear regression is a site where disturbances allow a

388 tree cover different from the one expected considering the climate conditions

389 only. In this case the ecosystem is denominated disturbance dependent (fire

390 dependent is one example). Conversely, if the action of fire and herbivores

391 induces on the vegetation only small modifications with respect to the state

392 predicted by the climate conditions, we refer to this ecosystem as perturbed

393 climate dependent.

394 Figure 5 shows that the 15 sites are located around two values of mean 395 annual rainfall, 400-500 [mm/yr] (L-L, H-L, and H-H sites) and 1160 [mm/yr]

396 (L-H sites), except for Mpala research center, site B5, with a mean annual 
397 rainfall of $360[\mathrm{~mm} / \mathrm{yr}]$ and Comoé National Park, site A4, that presents a 398 mean annual value of about $950[\mathrm{~mm} / \mathrm{yr}]$. Using the stability maps given 399 in Fig. 6, we compare the observed ecosystem composition with the steady 400 state derived by the model. The stability maps in the $b-f$ parameters space 401 are drawn at $p=500[\mathrm{~mm} / \mathrm{yr}]$ in Fig. 6(a), and at $p=1160[\mathrm{~mm} / \mathrm{yr}]$ in Fig. 402 6(b). Stability maps in Fig. 6, are obtained using the following values of the 403 parameters: $w_{1}=345[\mathrm{~mm}], \epsilon=20[1 / \mathrm{yr}], \tau_{T}=30[1 / \mathrm{yr}], \tau_{G}=10[1 / \mathrm{yr}]$, $404 \gamma_{T}=2[1 / \mathrm{yr}], \gamma_{G}=200[1 / \mathrm{yr}], \delta_{T 0}=0.02[1 / \mathrm{yr}], \delta_{G 0}+g=2[1 / \mathrm{yr}]$ and $405 \delta_{F}=0.35$.

406 We assume an allometric relation between the density of browsers, $\mathcal{B}$, in 407 units of $\left[\mathrm{kg} / \mathrm{km}^{2}\right]$, and the removal coefficient, $b$, in units of $[1 / \mathrm{yr}]$, mathe408 matically defined by the power law function $b=a_{b} \mathcal{B}^{\alpha_{b}}$. This is supported by 409 the existing allometric law between the body mass of mammals and the cor410 responding metabolic rate characterized by an exponent approximately equal 411 to 0.7, (Schmidt-Nielsen, 1984, Dodds et al., 2001, White and Seymour, 2003, 412 Kolokotrones et al., 2010). Here the parameters of the allometric equation are 413 calculated as follows. The yegetation removal term - bT causes a reduction 414 of the tree extinction time, quantified in $\exp \left(-\left(\delta_{T 0}+b\right) t\right)$. Thus if we assume 415 that in presence of a 'low' browsers density, say of $100\left[\mathrm{~kg} / \mathrm{km}^{2}\right]$, the trees 416 extinction time is reduced of $33 \%$, and a 'high' density, say of $900\left[\mathrm{~kg} / \mathrm{km}^{2}\right]$, 417 the reduction is of $66 \%$ (with a reference value of $\delta_{T 0}=0.02[1 / \mathrm{yr}]$ ) then 418 the corresponding estimates are $b=0.01[1 / \mathrm{yr}]$ and $b=0.04[1 / \mathrm{yr}]$. These 419 couples of $b$ and $\mathcal{B}$ allow to estimate the parameters of the allometric rela420 tionships using the Least Squares Method: $a_{b}=5.82 \cdot 10^{-4}\left[\left(\mathrm{~km}^{2} / \mathrm{kg}\right)^{\alpha_{b}} / \mathrm{yr}\right]$ 421 and $\alpha_{b}=0.62$ dimensionless. The estimate of the exponent $\alpha_{b}$ (even though 
422 an approximation) is not very different from the one used for the methabolic 423 rate-mass law $(\approx 0.7)$. Note that a similar relation could be obtained to 424 link the grazers density with the removal coefficient $g$. The allometric rela425 tionship allows to convert the browsers densities observed in the 15 sites of 426 interest into values of the removal coefficient $b$. Figure 6 gives the location 427 of the sites in the $b-f$ plane.

428 The 15 sites considered have been located on the stability maps according 429 to the observed values of mean annual rainfall, browsers density, and fire 430 return period, see Table 1 . Note that for sites where the fire return period 431 is relatively long and not given specifically (i.e., given as disequalities $>10$, $432>20,>50$ years in Table 1$)$, we have assumed $f=0[1 / \mathrm{yr}]$.

433 Each site falls within a stability region according to the estimated param434 eters' values. Clearly, changes in the parameters' values can cause changes 435 in the stability region to which a site pertains.

436 We have performed, for each site, a sensitivity analysis varying (increasing 437 and decreasing) one parameter at the time until the stability region changes, 438 obtaining a range of variability for each parameter.

439 This analysis allows to characterize, locally, which parameter is to be con440 sidered 'stiff' (i.e., a small variation in the parameter value causes a structural 441 change in the stable steady state) and which 'sloppy' (i.e., a small variation 442 of the parameter does not correspond a structural change of the steady state) 443 in the sense of Gutenkunst et al. (2007).

444 According to the model, Eq.(1), and in order to reduce the number of 445 parameters to be investigated, we have grouped together $p$ and $w_{1}$ as $p / w_{1}$, $446 \delta_{T 0}$ and $b$ as $\delta_{T 0}+b$, and $\delta_{G 0}$ and $g$ as $\delta_{G 0}+g$. Note that a parameter 
447 could behave asymmetrically under increasing or decreasing of its value, i.e., 448 a parameter could be sloppy on the right side (increasing its value) and stiff 449 on the left side (decreasing its value). Here, for simplicity, we have classified 450 a parameter as stiff in average if its range of variability normalized by the 451 parameter value is below 3.5, otherwise it is considered sloppy. Here we have 452 considered 10 as the maximum magnification factor of a parameter.

$453 \quad$ Figure 7 presents the results of the sensitivity analysis for some keyed 454 sites: A1, B1, B2, C1, C2, C4 and C6. Site A1 is chosen as representative 455 of all the L-H sites. The site B1 is representative of the behavior of the 456 L-L sites B3 and B5, but not of the L-L site C6. The sites B2 and C4 are 457 representative of the behavior of the sites B4 and C5 respectively. Figure 7 458 will be discussed in the light of the disturbance regimes in the next section 459 where we examine separately the four different combinations of disturbances.

$460 \quad L-L$ sites

461 In Fig. 5 L-L sites $(\bullet)$ are located close to the piecewise linear regression 462 indicating that these are climate dependent ecosystems. The low level of 463 browsing and fire disturbances makes the woody cover of these sites mainly 464 dependent by the mean annual rainfall. In the stability map (Fig. 6(a)), 465 obtained for $p=500[\mathrm{~mm} / \mathrm{yr}]$, sites B1 and B3 fall in the forest region and 466 site $\mathrm{C} 6$ in the savanna region close to the boundary with the forest. The 467 woody cover is $41.3 \%$ and $45 \%$ respectively in sites B1 and B3, and $51.9 \%$ 468 in site C6, see Table 1 and Fig. 5. The fact that the sites B1 and B3, 469 observed as savannas, fall within the forest stability region can be explained 470 considering the results of the sensitivity analysis. From this, it is possible to 471 observe that 1 ) the parameters $\delta_{T 0}+b$ and $\gamma_{G}$ are stiff for sites B1 and B3; 
472 2) the stability region of these sites changes from forest to savanna if $\delta_{T 0}+b$ 473 or $\gamma_{G}$ slightly increase. Concerning site C6, the stiff parameters are $\gamma_{T}$ and $474 \delta_{G 0}+g$, Fig. 7 , and the stability region of $\mathrm{C} 6$ changes from savanna region 475 to forest if small increases of $\gamma_{T}$ or $\delta_{G 0}+g$ occur, from savanna to grassland 476 if $\gamma_{T}$ decreases. These results are coherent with the position of these sites 477 close to the boundary between forest and savanna in the stability map, Fig. $4786(\mathrm{a})$.

$479 \quad H$ - $L$ sites

480 H-L sites, namely B2, B4, C1, C2 and C3 (o in Fig. 5) receive approxi481 mately the same mean annual rainfall of L-L sites, but have a lower woody 482 cover. The high level of browsing pressure makes the ecosystems perturbed 483 climate dependent. All the H-L sites belong to the savanna region, as ex484 pected, Fig. 6 (a).

485 The sensitivity analysis identifies $\epsilon, \tau_{G}$ and $\delta_{T 0}+b$ as stiff parameters for 486 sites $\mathrm{B} 2$ and $\mathrm{B} 4, \gamma_{T}$ and $\delta_{G 0}+g$ for sites $\mathrm{C} 1$ and $\mathrm{C} 3$, and $\delta_{T 0}+b$ for site $\mathrm{C} 2$. 487 For sites B2 and B4 a small increase of one among $\epsilon, \tau_{G}$ and $\delta_{T 0}+b$ moves the 488 equilibrium from savanna to grassland, while a decrease of $\delta_{T 0}+b$ transforms 489 the ecosystem in forest. A variation of $\gamma_{T}$ induces a change in the stable 490 region of sites $\mathrm{C} 1$ and $\mathrm{C} 3$ : from savanna to forest if $\gamma_{T}$ is increased, and to 491 grassland if $\gamma_{T}$ is decreased. An increase in $\delta_{G 0}+g$ also causes a change from 492 savanna to forest for sites C1 and C3. Site C2 belongs to grassland region 493 when $\delta_{T 0}+b$ is increased, and to forest if the parameter value is reduced. 
494

495

496

497

498

499

500

501

502

503

504

505

506 507

508

510

511

512

513 a low browsing pressure $\left(\mathcal{B}=88\left[\mathrm{~kg} / \mathrm{km}^{2}\right]\right)$ would favour a forest state, but

514 the high fire frequency (in average one event/year) causes the reduction of

515 the woody cover. According to this combination of environmental forcings,

516 the model locates these savanna sites in the bistability region savanna/forest,

517 see Fig. 6(b). This result is supported by the geographical location of sites

518 A1, A2, and A3: they are close to the edge of the rainforest (Abbadie et al., 


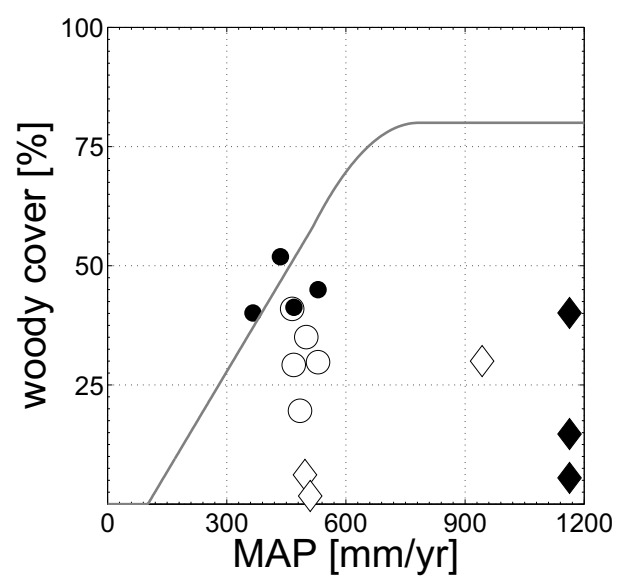

Figure 5: Representation of the 15 African sites in the mean annual rainfall - woody cover plane. Sites are represented according to the disturbances regime: L-L (•), H-L (०), H-H $(\diamond)$, and L-H $(\diamond)$.

519 2006). This is an example of bistability in space between savanna and forest 520 (Schröder et al., 2005).

521 For L-H sites, the sensitivity analysis shows that all the parameters, ex522 cept for $\tau_{T}$, are stiff, see Fig. 7: this is coherent with the hypothesis that 523 these savannas are fragile, and their vegetation structure can be completely 524 modified by small environmental variations. 


\section{b [1/yr]}

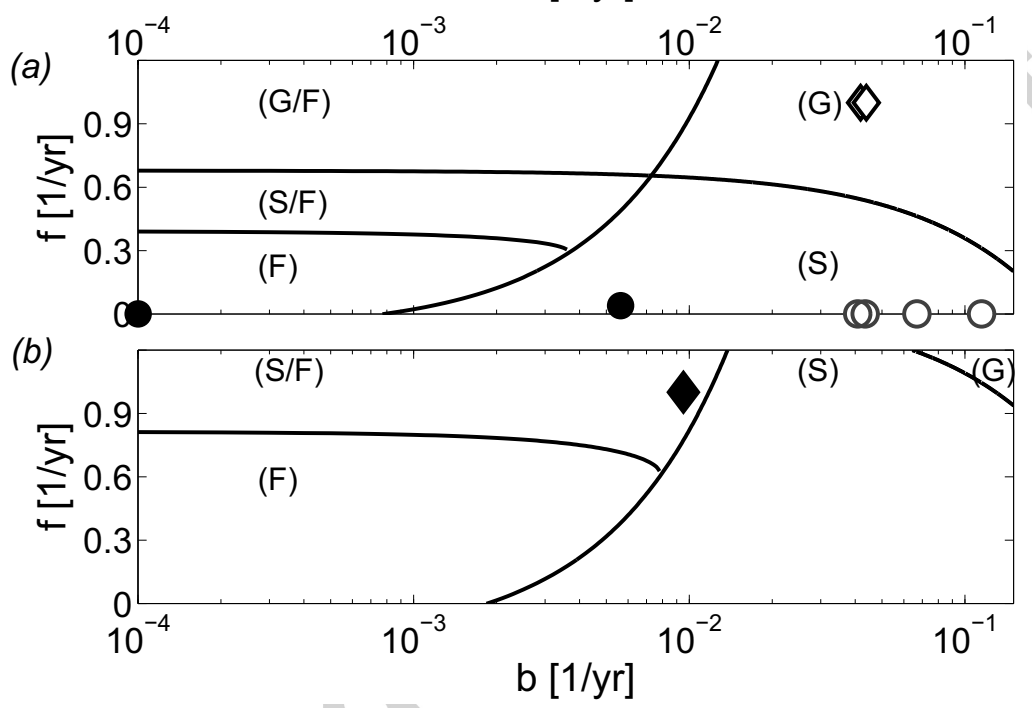

Figure 6: Representation of the 15 African sites in the herbivores - fire plane. Panel (a) shows the points in the stability map $b-f$ for $p=500[\mathrm{~mm} / \mathrm{yr}]$; Panel (b) gives the points in the stability maps $b-f$ for $p=1160[\mathrm{~mm} / \mathrm{yr}]$. The other parameters values are $w_{1}=345[\mathrm{~mm}], \epsilon=20[1 / \mathrm{yr}], \tau_{T}=30[1 / \mathrm{yr}], \tau_{G}=10[1 / \mathrm{yr}], \gamma_{T}=2[1 / \mathrm{yr}], \gamma_{G}=200$ $[1 / \mathrm{yr}], \delta_{T 0}=0.02[1 / \mathrm{yr}], \delta_{G 0}+g=2[1 / \mathrm{yr}], \delta_{F}=0.35$. Sites are represented according to the disturbances regime: L-L $(\bullet)$, H-L $(\circ), \mathrm{H}-\mathrm{H}(\diamond)$, and L-H $(\diamond)$. 


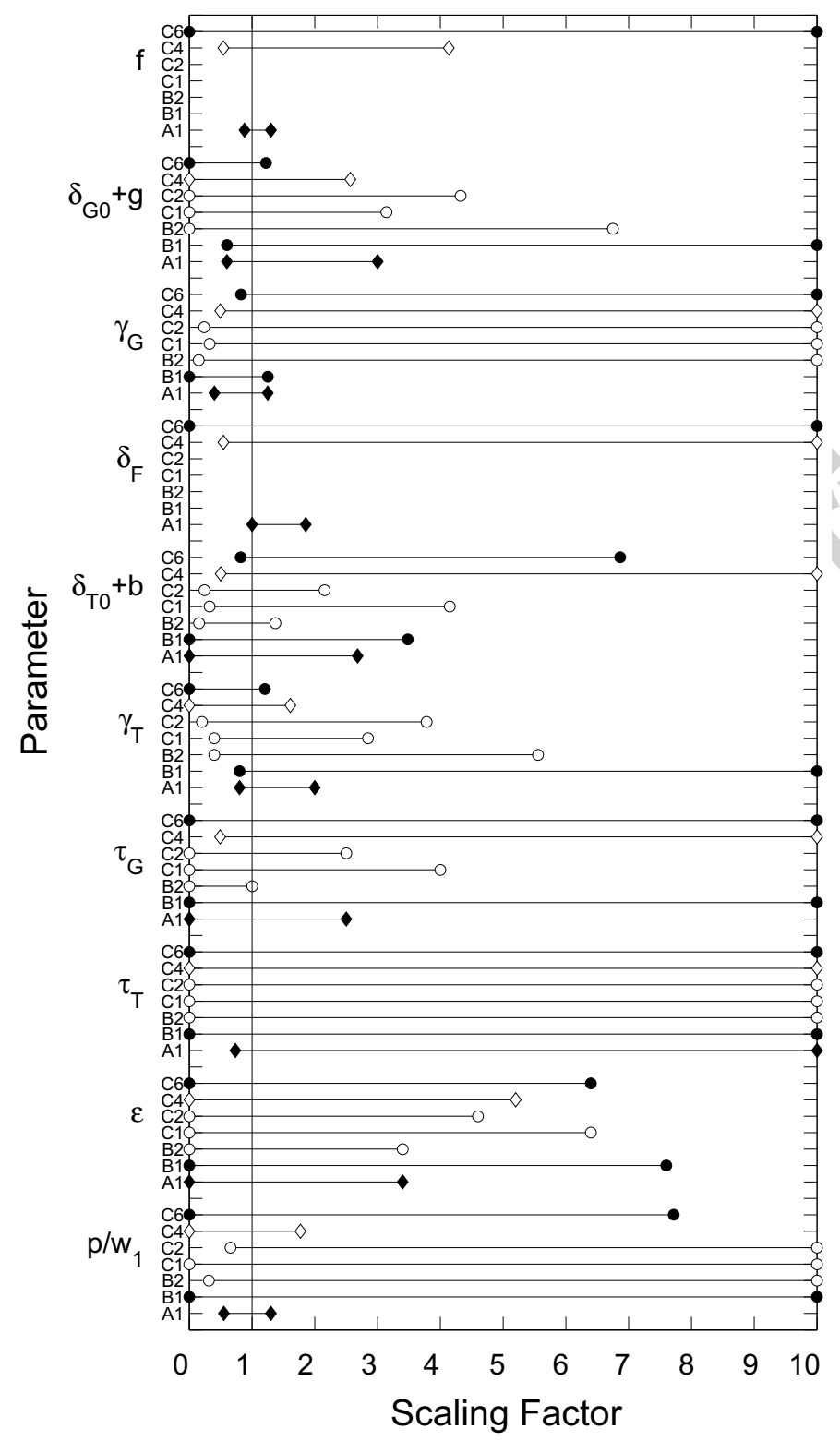

Figure 7: Scaling factor for each of the parameters in order to realize a change of the stable equilibrium, for the sites: A1, B1, B2, C1, C2, C4, C6. Values of the scaling factor $>1$ indicate a magnification of the parameter, while values $<1$ a reduction. Note that the sensitivity analysis for $f$ (and consequently for $\delta_{F}$ ) at B1, B2, C1, and C2, has not been represented because for these sites the fire occurrence is $\approx 0[1 / \mathrm{yr}]$. Symbols at the end points of each line stand for L-L $(\bullet), \mathrm{H}-\mathrm{L}(\circ), \mathrm{H}-\mathrm{H}(\diamond)$, and L-H $(\diamond)$ sites. 


\section{6. Conclusions}

526 We have investigated the conditions for the existence and the stability 527 of the savanna domain in the herbivores-fire parameter space, distinguishing 528 between browsing and grazing disturbances. This analysis is based on a 529 minimal ecohydrological model and shows how depending on the level of 530 disturbances savanna can be stable, or bistable with the forest.

531 In particular, when the innate tendency of trees to overtop grasses is 532 weakened by fire and/or browsing, and grasses are favored by low grazing 533 pressure, the existence of a savanna is mainly due to balanced competition 534 mechanisms. This happens when water is scarce and browsing pressure or 535 harvesting of trees is high. In this situation fire is not fundamental for the 536 tree-grass co-existence and the savanna stability. The system is a climate 537 dependent or a perturbed climate dependent ecosystem.

538 When the water availability and the grazing pressure are high and the 539 browsing pressure is low, savannas are maintained by fire, creating a demo540 graphic bottlenecks in tree population recruitment. In this case, savannas 541 are in bistable condition with forests, and must be considered a disturbance 542 dependent ecosystem, more precisely fire dependent ecosystem. Bistability

543 implies that, under certain conditions, a small variation of a parameter (such

544 as grazing and browsing parameters) can cause macroscopic changes in the 545 vegetation. These transitions can be sometimes irreversible.

546 This analysis suggests that the tree-grass co-existence in savanna is pos547 sible as a climate dependent ecosystem, or a disturbance dependent ecosystem 548 (classification introduced by Bond et al., 2003), or a perturbed climate de549 pendent ecosystem. However it is important to point out that a disturbance 
550 dependent savanna is a more fragile ecosystem than a climate dependent sa-

551 vanna, because the presence of bistability can induce abrupt transitions to

552 other vegetated states.

553 The analysis of data available in 15 African sites (referring to particularly

554 high or low values of fire occurrence and browsers density) helps to illustrate

555 the theoretical findings. Since the comparison between model and data is

556 conditioned by the uncertainty associated to parameters' estimates, we have

557 discussed and commented the results of the comparison within the framework

558 of a local sensitivity analysis of the parameters. This type of analysis is

559 fundamental in order to 1) quantify the reliability of the model predictions,

560 and 2) understand what happens if modifications in a parameter value occur.

\section{Acknowledgments}

562 The research was funded by Comune di Milano through BIO-DESCESA

563 project(BIOdiversity and DEsertification SCEnarios in South Africa under

564 climate change projections).

565 References

566 References

567 Abbadie, L., Gignoux, J., Le Roux, X., Lepage, M., 2006. Lamto, Structure, 568 Functioning, and Dynamics of a Savanna Ecosystem. Springer \& Verlag, 569 New York.

570 Accatino, F., De Michele, C., Vezzoli, R., Donzelli, D., Scholes, R., 2010. 
571 Tree-grass co-existence in savanna: Interactions of rain and fire. J. Theor. 572 Biol. 267, $235-242$.

573 Amarasekare, P., 2003. Competitive coexistence in spatially structured en574 vironments: a synthesis. Ecol. Lett. 6, $1109-1122$.

575 Augustine, D., McNaughton, S., 2006. Interactive effects of ungulate herbi576 vores, soil fertility, and variable rainfall on ecosystem processes in a semi577 arid savanna. Ecosystems 9, 1242 - 1256.

578 Barnes, R.F., 1983. The elephant problem in Ruaha National Park, Tanzania. 579 Biol. Cons. 26, $127-148$.

580 Baudena, M., D’Andrea, F., Provenzale, A., 2010. An idealized model for 581 tree-grass coexistence in savannas: the role of life stage structure and fire 582 disturbances. J. Ecol. 98, $74-80$.

583 Baxter, P.W.J., Getz, W.M., 2005. A model-framed evaluation of elephant 584 effects on tree and fire dynamics in African savannas. Ecol. Appl. 15, 1331 $585-1341$.

586 de Beer, Y., Kilian, W., Versfeld, W., van Aarde, R.J., 2006. Elephants and 587 low rainfall alter woody vegetation in Etosha National Park, Namibia. J. 588 Arid Environ. 64, $412-421$.

589 Ben-Shahar, R., 1993. Patterns of elephant damage to vegetation in northern $590 \quad$ Botswana. Biol. Cons. 142, 3099 - 3107.

591 Biggs, R., Biggs, H.C., Dunne, T.T., Govender, N., Potgieter, A.L.F., 2003. 
592 Experimental burn plot trial in the Kruger National Park: history, exper593 imental design and suggestions for data analysis. Koedoe 46, $1-15$.

594 Bond, W.J., Keeley, J.E., 2005. Fire as a global 'herbivore': the ecology and 595 evolution of flammable ecosystems. Trends Ecol. Evol. 20, 387 - 394.

596 Bond, W.J., Midgley, G.F., Woodward, F.I., 2003. What controls South 597 African vegetation - climate or fire? S. Afr. J. Bot. 69, 79 - 91.

598 Bond, W.J., van Wilgen, B.W., 1996. Fire and Plants. Chapman \& Hall, 599 London, UK.

600 Borgogno, F., D’Odorico, P., Laio, F., Ridolfi, L., 2009. Mathematical mod601 els of vegetation pattern formation in ecohydrology. Rev. Geophys. 47, 602 RG1005.

603 Bucini, G., Hanan, N.P., 2007. A continental-scale analysis of tree cover in 604 African savannas. Glob. Ecol. Biogeogr. 16, 593 - 605.

605 Caughley, G., 1976. The elephant problem - an alternative hypothesis. East 606 Afr. Wildl. J. 14, 265-283.

607 Coetzee, B.W.T., Tincani, L., Wodu, Z., Mwasi, S.M., 2008. Overgrazing and 608 bush encroachment by Tarchonanthus camphoratus in a semi-arid savanna. 609 Afr. J. Ecol. 46, $449-451$.

610 De Michele, C., Vezzoli, R., Pavlopoulos, H., Scholes, R.J., 2008. A minimal 611 model of soil water-vegetation interactions forced by stochastic rainfall in 612 water-limited ecosystems. Ecol. Model. 212, 397 - 407. 
613 Dodds, P.S., Rothman, D.H., Weitz, J.S., 2001. Re-examination of the 3/4614 law of metabolism. J. Theor. Biol. 209, $9-27$.

615 D'Odorico, P., Laio, F., Ridolfi, L., 2006. A probabilistic analysis of fire616 induced tree-grass coexistence in savannas. Am. Nat. 167, E79 - E87.

617 Dublin, H.T., 1995. Vegetation Dynamics in the Serengeti-Mara ecosystem: 618 the Role of Elephants, Fire and Other Factors, in: Sinclair, A.R.E., Arcese, 619 P. (Ed.), Serengeti II: Dynamics, Management, and Conservation of an 620 Ecosystem. The University of Chicago Press, Chicago, pp. $71-90$.

621 Fernandez-Illescas, C., Rodriguez-Iturbe, I., 2003. Hydrologically driven hi622 erarchical colonization-competition models: the impact of interannual cli623 mate fluctuations. Ecol. Monographs 73, 207-222.

624 Frost, P.G.H., Medina, E., Menaut, J.C., Solbrig, O.T., Swift, M., Walker, 625 B.H., 1986. Responses of savanna to stress and disturbance. Biol. Int. 626 Spec. Issue 10, $1-82$.

627 Gilad, E., Shachak, M., Meron, E., 2007. Dynamics and spatial organization 628 of plant communities in water-limited systems. Theor. Popul. Biol. 72, 214 $629-230$.

630 Govender, N., Trollope, W.S.W., van Wilgen, B.W., 2006. The effect of fire 631 season, fire frequency, rainfall and management on fire intensity in savanna 632 vegetation in South Africa. J. Appl. Ecol. 43, 748 - 758.

633 Gutenkunst, R.N., Waterfall, J.J., Casey, F.P., Brown, K.S., Myers, C.R., 
634 Sethna, J.P., 2007. Universally sloppy parameter sensitivities in systems 635 biology models. PLoS Comput. Biol. 3, e189.

636 Hanan, N.P., Sea, W.B., Dangelmayr, G., Govender, N., 2008. Do fires in sa637 vannas consume woody biomass? A comment on approaches to modelling 638 savanna dynamics. Am. Nat. 171, $851-856$.

639 Hobbs, R.J., Huenneke, L.F., 1992. Disturbance, diversity, and invasion 640 implications for conservations. Cons. Biol. 6, $324-337$.

641 Holdo, R.M., 2007. Elephants, fire, and frost can determine community 642 structure and composition in Kalahari woodlands. Ecol. Appl. 17, 558 643568.

644 Hovestadt, T., Yao, P., Linsenmair, K.E., 1999. Seed dispersal mechanisms 645 and the vegetation of forest islands in a WestAfrican forest-savanna mosaic 646 (Comoé National Park, Ivory Coast). Plant Ecol. 144, 1 - 25.

647 Klausmeier, C., 1999. Regular and irregular patterns in semiarid vegetation. 648 Science $284,1826-1828$.

649 Kolokotrones, T., Savage, V., Deeds, E.J., Fontana, W., 2010. Curvature in 650 metabolic scaling. Nature 464, 753756.

651 van de Koppel, J., Riekterk, M., Weissing, F., 1997. Catastrophic vegetation 652 shifts and soil degradation in terrestrial grazing systems. Trends Ecol. 653 Evol. 12, $352-356$.

654 van Langevelde, F., van de Vijver, C.A.D.M., Kumar, L., van de Koppel, J., 655 de Ridder, N., van Andel, J., Skidmore, A.K., Hearne, J.W., Stroosnijder, 
656 L., Bond, W.J., Prins, H.H.T., Rietkerk, M., 2003. Effects of fire and

657 herbivory on the stability of savanna ecosystems. Ecology 84, $337-350$.

658 Laws, R.M., 1970. Elephants as agents of habitat and landscape change in 659 East Africa. Oikos 21, $1-15$.

660 May, R.M., 1977. Thresholds and breakpoints in ecosystems with a multiple 661 of stable states. Nature 269, $471-477$.

662 McNaughton, S.J., Georgiadis, N.J., 1986. Ecology of African grazing and 663 browsing mammals. Annu. Rev. Ecol. Syst. 17, 39 - 65.

664 Moleele, N.M., Perkins, J.S., 1998. Encroaching woody plant species and 665 boreholes: is cattle density the main driving factor in the Olifants Drift 666 communal grazing lands, south-eastern Botswana? J. Arid Environ. 40, $667 \quad 245-253$.

668 Murphy, P.G., Lugo, A.E., 1986. Ecology of tropical dry forest. Annu. Rev. $669 \quad$ Ecol. Syst. 17, $67-88$.

670 O'Connor, T.J., 1995. Acacia karroo invasion of grassland: environmental 671 and biotic effects influencing seedling emergence and establishment. Oe672 cologia $103,214-223$.

673 Prins, H.H.T., van der Jeugd, H.P., 1993. Herbivore population crashes and 674 woodland structurein East-Africa. J. Ecol. 81, 305 - 314.

675 Rietkerk, M., Boerlijst, M.C., van Langevelde, F., HilleRisLambers, R., 676 van de Koppel, J., Kumar, L., Prins, H.H.T., de Roos, A., 2002. Self677 organization of vegetation in arid ecosystems. Am. Nat. 160, $524-530$. 
678 Roques, K.G., O'Connor, T.G., Watkinson, A.R., 2001. Dynamics of shrub 679 encroachment in an African savanna: relative influences of fire, herbivory, 680 rainfall and density dependence. J. Appl. Ecol. 38, 268 - 280.

681 Sankaran, M., Hanan, N.P., Scholes, R.J., Ratnam, J., Augustine, D.J., 682 Cade, B.S., Gignoux, J., Higgins, S.I., Le Roux, X., Ludwig, F., Ardo, 683 J., Banyikwa, F., Bronn, A., Bucini, G., Caylor, K.K., Coughenour, M.B., 684 Diouf, A., Ekaya, W., Feral, C.J., February, E.C., Frost, P.G.H., Hier685 naux, P., Hrabar, H., Metzger, K.L., Prins, H.H.T., Ringrose, S., Sea, W., 686 Tews, J., Worden, J., Zambatis, N., 2005. Determinants of woody cover in 687 African savannas. Nature 438, $846-849$.

688 Schmidt-Nielsen, K., 1984. Scaling. Why is animal size so important? Cam689 bridge University Press, Cambridge.

690 Scholes, R.J., Archer, S.R., 1997. Tree-grass interactions in savannas. Annu. 691 Rev. Ecol. Syst. 28, $517-544$.

692 Scholes, R.J., Walker, B.H., 1993. An African Savanna: synthesis of the 693 Nylsvley study. 1, Cambridge University Press, Cambridge.

694 Schröder, A., Persson, L., De Roos, A.M., 2005. Direct experimental evidence 695 for alternative stable states: a review. Oikos 110, 3 - 19.

696 Shmida, A., Burgess, L., 1988. Plant growth-form strategies and vegeta697 tion types in arid environments, in: Werger, M. J. A., Aart, P. J. M. V. 698 D., During, H. J., Verhoeven, J. T. A. (Ed.), Plant form and vegetation 699 structure. SPB Academic Pub, The Hague, pp. 211 - 241. 
700 da Silveira Lobo Sternberg, L., 2001. Savanna-forest hysteresis in the tropics. 701 Glob. Ecol. Biogeogr. 10, 369 - 378.

702 Skarpe, C., 1990. Structure of the woody vegetation in disturbed and undis703 turbed arid savanna, Botswana. Vegetatio 87, $11-18$.

704 Skarpe, C., Aarrestad, P.A., Andreassen, H.P., Dhillion, S.S., Dimakatso, T., 705 du Toit, J., Halley, D.J., Hytteborn, H., Makhabu, S., Mari, M., Marokane, 706 W., Masunga, G., Modise, D., Moe, S.R., Mojaphoko, R., Mosugelo, D., 707 Motsumi, S., Neo-Mahupeleng, G., Ramotadima, M., Rutina, L., Sechele, 708 L., Sejoe, T.B., Stokke, S., Swenson, J.E., Taolo, C., Vandewalle, M., 709 Wegge, P., 2004. The return of the giants: Ecological effects of an increas$710 \quad$ ing elephant population. Ambio 33, $276-282$.

711 Smit, G.N., 2004. An approach to tree thinning to structure southern African 712 savannas for long-term restoration from bush encroachment. J. Environ. 713 Manage. $71,179-191$.

714 Tilman, D., 1994. Competition and biodiversity in spatially structured habi715 tats. Ecology $75,2-16$.

716 Vezzoli, R., De Michele, C., Pavlopoulos, H., Scholes, R.J., 2008. Dryland 717 ecosystems: The coupled stochastic dynamics of soil water and vegetation 718 and the role of rainfall seasonality. Phy. Rev. E 77, 397 - 407.

719 Walter, H., 1971. Ecology of tropical and subtropical vegetation. Oliver and 720 Boyd, Edinburgh, UK. 
721 White, C.R., Seymour, R.S., 2003. Mammalian basal metabolic rate is pro722 portional to body mass ${ }^{2 / 3}$. Proc. Natl. Acad. Sci. U.S.A. 100, $4046-4049$.

723 Wiegand, K., Ward, D., Saltz, D., 2005. Multi-scale patterns and bush 724 encroachment in an and savanna with a shallow soil layer. J. Veg. Sci. 16, $725 \quad 311-320$.

726 Zimmermann, J., Higgins, S., Grimm, V., Hoffman, J., Linstder, A., 2009. 727 Grass mortality in semi-arid savanna: the role of fire, competition, and 728 self-shading. Perspect. Plant Ecol. Evol. Syst. 12, 1 - 8. 
Paper reference: YJTBI 6586

Editorial reference: YJTBI_JTB-D-11-00169

To be published in: Journal of Theoretical Biology

Highlights of the manuscript

- We investigate the existence and stability of savannas in the herbivores-fire space

- The analysis is based on a spatially implicit ecohydrological model

- The results show the types of savannas as function of the disturbance levels

- An application is discussed with the help of a local sensitivity analysis

- The comparison between model and data supports the theoretical findings 